\title{
Stage I Lung Cancer AJCC v8
}

National Cancer Institute

\section{Source}

National Cancer Institute. Stage I Lung Cancer AJCC v8. NCI Thesaurus. Code C136470.

Stage I includes: IA1: (T 1 mi, N0, M0); (T1a, N0, M0); IA2: (T 1b, N0, M0); IA3: (T 1c, NO, M0); IB: (T2a, NO, M0). T1 mi: Minimally invasive adenocarcinoma: adenocarcinoma (3 cm or less in greatest dimension) with a predominantly lepidic pattern and $5 \mathrm{~mm}$ or less invasion in greatest dimension. T1a: Tumor measuring $1 \mathrm{~cm}$ or less in greatest dimension. A superficial, spreading tumor of any size whose invasive component is limited to the bronchial wall and may extend proximal to the main bronchus also is classified as T1a, but these tumors are uncommon. T1 b: T umor measuring more than 1 $\mathrm{cm}$ but $2 \mathrm{~cm}$ or less in greatest dimension. T1 c: Tumor measuring more than $2 \mathrm{~cm}$ but 3 $\mathrm{cm}$ or less in greatest dimension. T2a: Tumor measuring more than $3 \mathrm{~cm}$ but $4 \mathrm{~cm}$ or less in greatest dimension. N0: No regional lymph node metastases. M0: No distant metastasis. (AJCC 8th ed.) 